\title{
UNJUST ENRICHMENT AND CONTRACT
}

Peter Jaffey*

\section{Introduction}

On the face of it, Benedetti $v$ Sawiris ${ }^{1}$ is a case on a narrow and technical point on the measure of the quantum meruit in the law of unjust enrichment, but it is significant beyond this in what it says, or implies, about the law of unjust enrichment generally and its relationship with the law of contract.

The facts of the case are complicated, but so far as they are relevant for present purposes they can be summarised quite simply. Benedetti approached Sawiris to see if he would be interested in collaborating in the acquisition of a company called Wind. The original idea was that Sawiris would become a shareholder along with Benedetti in a new company established to take over Wind, but most of the funding for the acquisition would come from other investors that Benedetti would find. This was set out in the Acquisition Agreement. It seems to have been envisaged that Benedetti would profit from the venture as an investor or director in the new company when the Acquisition Agreement was implemented. In the end, however, no other investors were found and so the Acquisition Agreement was abandoned. Sawiris decided to continue with the takeover by providing the funding himself, and Benedetti continued to work on his behalf towards the acquisition on this new basis, though there was no longer any written contract governing the relationship between them, and there was no explicit agreement for Benedetti's remuneration. The acquisition of Wind by Sawiris was eventually successful. Although Sawiris accepted that Benedetti was entitled to be paid for what he had done, the two parties could not agree on the amount, and Benedetti sued Sawiris on various bases including contract and unjust enrichment. By the time the matter reached the Supreme Court, the only issue was the measure of recovery in unjust enrichment, Sawiris having accepted that he was liable in unjust enrichment, and the other bases, including contract, having been rejected by the lower courts.

\footnotetext{
*Brunel Law School.

${ }^{1}$ [2013] UKSC 50.
} 


\section{The contractual context}

The significance of the claim in unjust enrichment cannot be appreciated except in its contractual context. Normally payment for the supply of goods or services is governed by contract. A party may do something for the another party without a contract, knowing that he is not entitled to be paid for it, though perhaps hoping that he will be paid, or that he will subsequently secure a right to be paid by making a contract. For example, a window cleaner might clean a window to demonstrate the quality of his work, or an architect might send a plan to show his idea for a project. In this way, a supplier might do work and incur costs, and he might confer a benefit on the other party, but the traditional understanding, certainly so far as contract law is concerned, is that there is no right to be paid.

Consider an alternative possible rule: one party, the supplier, may simply confer a benefit on another party, the buyer, and then, if he intended to be paid rather than to confer a gift, he is entitled to be paid for his work, the price to be set by a court if it is not agreed by the parties. It goes almost without saying that this would in general be a far worse rule. One might say in its favour that the purpose of a contract is to achieve a mutually beneficial exchange of goods or services for payment, and that this alternative rule would also achieve this, provided that the price set is fair. A fair price would be a price that is less than the value the recipient attributes to the benefit he has received, and enough to cover the supplier's costs and leave him what he would regard as a sufficient return for what he did in providing the benefit. But of course different people have different resources and different preferences, and are in different circumstances with different plans, and so they may place very different values on the benefit or on an acceptable return for the work. For many possible recipients of benefits there would be no price that they would be willing to pay that the supplier would consider sufficient, and so no fair price at all, and even where there might be a fair price it would be very difficult to say what it is. The advantage of requiring an agreement is, of course, that the parties take on the responsibility for agreeing the terms of 
exchange, so that someone only has to pay for a benefit if he has determined that it is worth at least what he has to pay for it under the contract, and a supplier will perform only if he has determined that the price is acceptable. The contractual approach, first, respects the autonomy of the parties over the use of their resources; secondly, it means that the price and the remedy awarded reflect the parties' valuation of the costs and benefits of the exchange; and, thirdly, it allows the parties to allocate the risks of changes in the costs and benefits of the exchange.

However, there are circumstances in which the alternative rule might be appropriate. Where it is impossible or impracticable for the parties to negotiate with each other, and it is also clear that they would have negotiated and reached an agreement if they could have done, it may be justified to recognise a liability for payment. This is typically the position in the case of 'necessitous intervention', where the claimant saves the defendant or his property from harm in an emergency where negotiation was impossible and the defendant would certainly have sought and paid for assistance if he could have done. ${ }^{2}$ One might treat in a similar way the situation where goods or services are supplied but no genuine agreement is reached because of a mistake by one or other or both parties. Although the alternative rule may be defensible in these types of case, if the contractual rule is adopted (as of course it should be and has been), it is surely clear that there is no room to apply the alternative rule where there is no impediment to contracting and no mistake. The alternative rule should not operate to allow a supplier simply to confer a benefit and demand payment without taking the trouble to make an agreement first. This would completely undermine the process of negotiation leading to contract, which is based on the assumption that only if an agreement is reached can there be any liability to pay for a benefit conferred. It would be bound to create uncertainty and to lead to opportunistic and disingenuous behaviour in tendering and negotiations.

If and when the alternative rule does apply, it is illuminating to say that, in a manner of speaking, the court makes a contract for the parties. Of course this is not literally the case - it is in

\footnotetext{
${ }^{2}$ See generally A Burrows, The Law of Restitution (Oxford: OUP, $3^{\text {rd }}$ edn, 2011), ch 18.
} 
the nature of an agreement that it can only be made by the parties. But the rationale of the law is to secure a mutually beneficial exchange of goods or services for payment, which is what the parties try to secure through a contract. One can reasonably say that liability in the absence of a contract is assessed by extension from or by analogy with contract. One might say that there is an imputed or simulated contract. ${ }^{3}$ There is no fiction in the sense of applying a rule that operates on the basis of facts that are taken to be true but are not. There is no false assumption that there is in fact an agreement.

Thus one might say that the contractual context includes the basic rules (1) that parties who make an agreement are bound by it, (2) that, where the parties have made an agreement, liability for payment is governed by the agreement, (3) that in the absence of an agreement parties are not liable to pay for a benefit if contracting was feasible, i.e. there was no mistake or impediment to contracting, and, one might add, that (4) where contracting was not feasible there may sometimes be a liability for payment by analogy with contract to secure a fair exchange. One might say that these rules form an extended law of contract, or at least a contract-oriented legal regime governing exchange. ${ }^{4}$ These rules, or at least the first three, are surely taken for granted by ordinary business people in negotiating their contracts. They represent at least the starting point of the traditional approach to contract. The problem now, as Benedetti demonstrates, is that this traditional position is being put at risk, to no obvious advantage, by recent developments in the law of unjust enrichment. $^{5}$

\footnotetext{
${ }^{3}$ There are a number of contractually-oriented approaches in the literature for this type of case, including $S$ Stoljar, The Law of Quasi-Contract (Sydney: The Law Book Co, $2^{\text {nd }}$ ed, 1989); S Levmore, 'Explaining Restitution' 71 Virginia Law Review 65 (1985); IM Jackman, The Varieties of Restitution (Annandale: Federation Press, 1998); P Jaffey, The Nature and Scope of Restitution (Oxford: Hart, 2000), ch 3; S Hedley, 'Implied Contract and Restitution' (2004) 63 CL 435; and more recently D Priel, 'In Defence of Quasi-Contract' (2012) 75 MLR 54. See also D Campbell, 'A Relational Critique of the Third Restatement of Restitution §39' 68 Washington and Lee Law Review 1063 (2011).

${ }^{4}$ Above n5.

${ }^{5}$ See further P Jaffey, 'Restitutionary Remedies in the Contractual Context' (2013) 76 MLR 429. Cf R Grantham \& CEF Rickett, 'On the Subsidiarity of Unjust Enrichment' (2011) 117 LQR 273; see also RA Havelock 'The Valuation of Enrichment in the Supreme Court: Benedetti v Sawiris' (2013) 21 RLR (forthcoming).
} 
There is another preliminary point to make about the legal context before addressing Benedetti directly. Claims arising under this contract-oriented regime governing exchange can be contrasted with an altogether different type of claim. If $\mathrm{C}$ owns property that comes into the possession of $D$ without a valid transfer of ownership, $C$ can normally recover it. (This is not of course as straightforward as it might seem but it is not necessary to pursue it here). $C$ recovers what he was already entitled to and there is no injustice to $D$ who was never entitled to it. Where $C$ pays money to $D$ by mistake or where C's money reaches $D$ without C's authority for the transfer, $C$ can recover the value of the transfer. Here $\mathrm{C}$ may not recover the same tangible thing, and the claim may not be understood as a matter of property law, but nevertheless the claim recovers for $\mathrm{C}$ something that he originally had, which was transferred to $D$ and can be returned. The thing recovered is the money as wealth or intangible value, which existed before the transfer and persists after D has received it. It subsists independently of $C$ and $D$ and so can be transferred from $C$ to $D$ and returned to $\mathrm{C}$. This is so whether the money is embodied in a tangible form or takes an intangible form such as an investment or a contractual right of payment. Some would say that this sort of claim is still fundamentally a matter of property, but, in any case, it has essentially the same rationale. It protects C's pre-existing right to his money.

This is quite different in principle from a claim for payment for services. The provision of services does not involve the passage to $D$ from $C$ of a thing, tangible or intangible, to which $C$ was entitled and that is capable of being returned to him. The provision of services may cost $\mathrm{C}$ nothing and the benefit to $D$ may not be in the form of anything that comes from $C$ and endures in $D$ 's hands and is capable of being restored to $C$. The services may simply provide D with a transient experience, for example. Even if they do cause an enduring change or generate a thing for $D, D$ does not acquire something that $\mathrm{C}$ previously had. Payment for services is not the return of something transferred. The two types of claim raise quite different issues, in the case of a mistaken or unauthorised transfer the appropriate regime for the protection of pre-existing property and wealth, and in the case of 
services the appropriate regime for exchange as discussed above. ${ }^{6}$ Unfortunately, the law of unjust enrichment treats a non-contractual claim for payment for services as analogous to the claim to recover a mistaken payment, and assimilates these very different types of claim under a common framework for unjust enrichment. This obscures the distinction between them, and undermines the contractually-oriented regime for claims for payment for services.

\section{The basis for the unjust enrichment claim in Benedetti}

In Benedetti the claim was in unjust enrichment, and, on the face of it, the effect was to allow a claim for payment for services provided, without reference to any agreement, in the absence of a mistake and with no impediment to contracting, even though the parties were dealing with each other and possibly in negotiation over terms. As discussed above, this is inimical to the law of contract and should be a matter for serious concern. The underlying problem is that the law of unjust enrichment obscures the true character of a claim for payment for services.

This was not exactly the problem in Benedetti, however. The position is more complicated. It seems that in Benedetti there was actually an agreement between the parties. As Lord Neuberger put it, there was a contract 'arising from the parties' words and conduct ...', and 'it must be at least arguable that there would be implied into the contract a term that [Benedetti] should be paid a reasonable sum', ${ }^{7}$ which would normally be described as a contractual quantum meruit. In my view it would have been preferable if the matter had been dealt with in this way, though possibly this avenue was not open to the Supreme Court.

One might think that under the unjust enrichment approach the presence of this agreement was irrelevant, but this was not actually the case. Curiously it appears that the presence of the agreement between the parties was actually a necessary condition of the unjust enrichment claim.

\footnotetext{
${ }^{6}$ See generally Stoljar, above n3, and the other works referred to in n3.

${ }^{7}$ At [177].
} 
For an unjust enrichment claim, there must be an 'unjust factor'. ${ }^{8}$ This is the category of reason that justifies a claim for restitution for unjust enrichment in the circumstances in question. The unjust factor here was given as 'failure of consideration', which in this context is understood to mean not that there is no consideration in the ordinary contractual sense, but that the benefit is conferred on a basis that fails, or on a condition that has not been satisfied..$^{9}$ There is room for argument over what exactly this means. Can a supplier unilaterally and privately specify that he is supplying a benefit on the basis that he is to be paid for it, and then demand payment? This would exactly reproduce the alternative rule. In fact, it seems to be accepted that there can be a failure of consideration only when there is an agreement, of some sort, between the parties. ${ }^{10}$ Presumably the rationale for this is to protect the recipient's freedom to choose what benefits to pay for, to ensure that the exchange is beneficial to him - the same reason, of course, why it is normally said, in the contractual context, that, rather than applying the alternative rule, a contractual agreement is required for liability to arise.

Thus, despite appearances, the position in Benedetti was not that the alternative rule was applied in circumstances where the parties could perfectly well make an agreement. The claim was actually based on agreement, but in the form of a claim in unjust enrichment. The effect of invoking the law of unjust enrichment is simply to get around restrictive conditions or remedial limitations in the law of contract, though again this is obscured by the understanding of the claim as a claim to recover a transfer. The law would be more coherent if it either denied a claim or developed the law of contract to allow a contractual claim based on the agreement. ${ }^{11}$ This is of direct relevance to Benedetti, because, as discussed below, the problem in the case is that an essentially agreementbased claim was forced into an unjust enrichment framework that was not really adapted for it.

\footnotetext{
${ }^{8}$ The concept of the unjust factor is due to P Birks, An Introduction to the Law of Restitution (Oxford: OUP, rev edn, 1989).

${ }^{9}$ See for example Lord Reed at [86].

${ }^{10}$ This seems to have been the view in this case and has support in the literature: e.g. Burrows, above n2, 372 .

11 This has commonly been argued by opponents of the unjust enrichment approach though it now appears in Burrows, above $\mathrm{n} 2,372$.
} 
An analogous problem arises where an agreement has given rise to a valid contract. It is said that there can sometimes be a non-contractual quantum meruit in respect of some part of the performance of the contract. This was not in issue in Benedetti but it receives implicit support. ${ }^{12}$ Again it is based on the thought that the principle of unjust enrichment provides an alternative basis for making someone liable to pay for a benefit that he has agreed to pay for, which can arise concurrently with a contractual claim based on the agreement, based presumably on the assumption that the claim serves to recover a transfer. But it is difficult to see what basis there is for requiring payment for part performance of the contract other than the agreement itself or why a claim based on the agreement should not be regarded as contractual. ${ }^{13}$

\section{The remedy}

The legal issue identified by the Supreme Court was apparently quite simple. For the purposes of the claim in unjust enrichment, the measure of recovery was the value of the benefit received by Sawiris from Benedetti, and the question was whether this benefit should be measured 'objectively' or 'subjectively'. According to the court, the objective measure of the value of services is their market value, whereas the subjective measure is the value actually attributed to them by the recipient, which could be higher or lower than the market price. If a recipient values the benefit at less than the market values it, the issue is whether he can rely on a principle of 'subjective devaluation' to reduce the measure of recovery from the market price, and if he values it more highly than the market, the question is whether the claimant-supplier can insist on 'subjective revaluation' to justify a higher measure of recovery. ${ }^{14}$ Here it was subjective revaluation that was in issue, because Benedetti argued that there was evidence that Sawiris valued the services more highly than the market, but subjective devaluation was considered first, as a step in the argument and because it is the more common case.

\footnotetext{
12 See e.g. Lord Clark at [31].

${ }^{13}$ As argued in Jaffey, above $\mathrm{n} 5$.

${ }^{14}$ These expressions are again derived from the unjust enrichment literature, in particular Birks, above n8, 109-10.
} 
One problem concerning valuation is not explicitly addressed in the judgements. As I have said, the unjust enrichment claim is conceived of as undoing or reversing a transfer and thereby removing a benefit, as in the case of a mistaken payment, but in this sort of case the claim is better understood as securing payment for a benefit and so effecting an exchange. The real issue is not the value of the defendant's benefit or gain, but the appropriate price for it. This is clear where the quantum meruit is contractual, and it is equally true here where it is non-contractual. The objective value or objective price is the ordinary market price. However, as the court discussed, there may be a specialist market price, the price in a sub-market for suppliers and buyers with the particular features of the parties involved. ${ }^{15}$ Furthermore, where there is no actual market at all, one can ask what a reasonable person in the recipient's position would have had to pay. ${ }^{16}$ As I understand this, it is an assessment of what would have been agreed between the parties taking account of objective or public circumstances, which is described as a market price, though it is not a price ascertained from an actual market. These are variants of the objective price.

By contrast, the subjective price is the price that would have been agreed by these parties in the light of all the factors that would actually have influenced them in deciding whether to contract, including their private preferences, plans and resources. ${ }^{17}$ If the parties do actually negotiate, they may typically accept the market price if there is one, but they may instead arrive at a different price, a subjective price in this sense. The market price merely represents the price at which supply meets demand. It does not mean that there is necessarily a mutually-beneficial exchange for the parties at that price or that there cannot be a mutually beneficial exchange at another price. A buyer might insist on a lower price and a supplier might well agree to a lower price, even though he makes less than he would at the market price, if this happens to be the best option open to him in the circumstances.

\footnotetext{
${ }^{15}$ Lord Clarke at [17]; Lord Reed at [111].

${ }^{16}$ Lord Clarke at [17].

${ }^{17}$ On this understanding the subjective valuation is not really the recipient's 'subjective opinion of the value' (at [12], per Lord Clarke), which suggests that the recipient's valuation is a judgement of the actual, objective value.
} 
In Benedetti, if there had been a contractual claim based on the agreement, the remedy would have been a contractual quantum meruit. This is 'reasonable payment', normally understood to be payment at the market price. ${ }^{18}$ The rationale is presumably that this was implicitly agreed. Parties who contract without agreeing a specific price can be taken to have agreed to an objective price, in the sense of the market price or the price that a reasonable person in the buyer's position would have had to pay. Since they chose not to negotiate a price, it seems right that neither party should be able to insist on the subjective price that they might have negotiated in the light of additional private considerations. However, if a supplier confers a benefit in circumstances where there was no agreement but the recipient is liable under the alternative rule, because it was impossible to negotiate or because of mistake, normally the market price should apply again, but here the assumption must be not that the parties implicitly agreed to this, but that they would have agreed to it if they had negotiated. Furthermore, it may well be justified to adjust the price on the basis that, if the parties had been able to negotiate, they would have agreed a higher or lower price than the objective price in the light of private considerations. In other words, here a subjective price is appropriate.

The claim in Benedetti was not in contract but in unjust enrichment. One might think that, if one were to adopt a rule for a non-contractual, unjust enrichment claim, it should be the approach applicable for the alternative rule, in the absence of an agreement, so that the court should be prepared to depart from the market rate according to subjective devaluation or revaluation. However, the court said that the starting point for measuring a benefit in unjust enrichment is the objective measure. ${ }^{19}$ Lord Reed offered the following explanation for this: ${ }^{20}$

The object of the remedy ... is ... to correct the injustice arising from the defendant's receipt of the claimant's services on a basis that was not fulfilled. That injustice cannot be corrected

\footnotetext{
${ }^{18}$ See eg E Peel, Treitel The Law of Contract (London: Sweet \& Maxwell, $13^{\text {th }}$ edn, 2011), 22-020.

${ }^{19}$ Lord Clarke at [15]-[16], Lord Reed at [99], Lord Neuberger at [180].

${ }^{20}$ At [99]. See also at [123]. The other judges did not offer any comparable explanation.
} 
by requiring the defendant to provide the claimant with the reward that either party might have been willing to agree. That is because, in the absence of a contract, neither party's intentions or expectations can be determinative of their mutual rights and obligations. Nor can the court make the parties' contract for them: a contract which might have included many other terms and conditions besides a price. In such circumstances the unjust enrichment arising from the defendant's receipt of the claimant's services can be corrected only by requiring the defendant to pay the claimant the monetary value of those services, thereby restoring both parties, so far as a monetary award can do so, to their previous positions.

This line of argument might be appropriate for a claim to recover a mistaken payment of money. For a payment of money, the transfer typically has a value that corresponds to the claimant's loss and the defendant's gain. But for a supply of services, with respect, it is surely not true to say that the 'monetary value of the services', meaning the market price, is in general a measure of what the claimant, $C$, has lost and the defendant, $D$, has gained, or that, by requiring $D$ to pay this sum to $C$, the law restores $C$ and $D$ to their original positions. This is the error discussed above of conflating a claim for payment for services, which gives effect to an exchange, with a claim to recover a transfer. Benedetti concerned an exchange, not a transfer.

With respect to an exchange, the appropriate remedy is not the 'monetary value of the services', as if it were the value of a transfer, but a fair price, a price that will render the exchange mutually beneficial. If there was an agreement, it is reasonable to take the market price as the price that should be paid, and the reason is not that it is an objective measure of the value of a transfer, but that it is reasonable to infer that this is what the parties agreed. The market price is not in any sense a neutral price in the sense of being necessarily a fair or 'even-handed' ${ }^{21}$ price between these two parties as if it were the value of a transfer. Although Lord Reed proceeded on the basis that the

\footnotetext{
${ }^{21}$ Lord Reed at [123].
} 
claim was not based on agreement, it seems to me that it is only because there was an agreement that it was justified to use the market price. If one were to ignore the agreement, it would seem appropriate to try and determine a subjective price in the light of whatever subjective factors would have influenced the parties if they had negotiated, since this in the end would be a better way to determine what would be a fair price as between these two parties. This counterfactual exercise of determining a subjective price in the absence of agreement does not of course draw on actual intentions and expectations.

Consistently with this, the court proceeded to say that, although the objective measure is the standard measure in unjust enrichment, subjective devaluation should generally be allowed. ${ }^{22}$ The reason for this is not explored in the judgements. Lord Reed's argument quoted above seems to imply that it should not be available. In Benedetti, subjective revaluation was in issue rather than subjective devaluation. Although the court favoured subjective devaluation, it was against subjective revaluation. ${ }^{23}$ The reason given was that subjective revaluation is unnecessary to protect the defendant. However, the question is whether fairness to the claimant calls for subjective revaluation if this will not be unfair to the defendant. If a claim is allowed where there is no agreement, there may be an argument for allowing the claimant the benefit of a higher price if the parties would have agreed to this.

In any case, where there is 'free acceptance', according to the court, the law reverts to the objective measure. The reason appears to be that, if the defendant 'freely accepted' the benefit, he cannot then deny its objective value and insist on a subjective valuation. This argument might be attractive if the defendant freely accepted the benefit on the understanding that he would have to pay the market price for it, but not if his understanding was that he would not have to pay for it at all, or that he would be liable at a lower price than the market price. ${ }^{24}$ Thus Lord Reed preferred

\footnotetext{
22 Lord Clarke at [18]; Lord Reed at [113]-[119].

${ }^{23}$ Lord Clarke at [30].

${ }^{24}$ Lord Clarke at [25]. As pointed out by Havelock, above n5, free acceptance has not generally found support in the literature, either as an unjust factor or as a measure of benefit.
} 
what he called the 'choice of benefit' principle. ${ }^{25} \mathrm{~A}$ defendant's liability should depend on the basis on which he chose to accept the benefit. ${ }^{26}$ This approach is preferable, according to Lord Reed, because it protects the defendant's autonomy, in the sense of his right to control the deployment of his resources. This seems correct as far as it goes, but the defendant surely cannot unilaterally stipulate the basis on which the benefit is supplied, any more than the claimant can. The only way to uphold the autonomy or freedom to choose of both parties is to base the claim on agreement. The choice of benefit principle to protect autonomy is really what is behind the traditional requirement that claims for payment for benefits conferred must be based on agreement, understood to mean confining the claim to contract. Thus again the true justification for applying a market rate without subjective devaluation in Benedetti is that the claim was based on agreement.

Lord Reed said he preferred the choice of benefit principle to the principle of subjective devaluation, but these are not really alternatives. As I have suggested, the choice of benefit principle really implies that agreement should be preferred as the basis for a claim for payment for a benefit, where agreement is feasible, whereas the principle of subjective devaluation - the principle that the subjective price should be preferred in order to take account of the particular preferences, plans and resources of the parties in determining the value of the benefit - is properly applicable, it seems to me, where it is justified to allow a claim in the absence of an agreement, under the alternative rule.

\section{The structure of the law on claims for payment for benefits conferred}

The law of unjust enrichment is becoming increasingly well established in English law, but Lord Reed noted that 'the most suitable analytical scheme' for this part of the law of unjust enrichment is still a matter for argument. ${ }^{27}$ In this sort of situation, the law seems strikingly and unnecessarily complex. For comparison, here is a simple scheme for the law of claims for payment for benefits conferred

\footnotetext{
${ }^{25}$ At [117].

${ }^{26}$ Lord Clarke at [26] rejects what he understands as Lord Reed's all-or-nothing approach, either the market price or nothing, but Lord Reed at [115] does not appear to understand the choice of benefit approach in this way.

${ }^{27}$ At [119].
} 
through the supply of goods or services, consistent with the contract-oriented analysis suggested earlier, which is in my view closer to the traditional common law. (1) Where there is an agreement that meets the conditions for a contract, there can be a contractual claim. (2) In the absence of such an agreement, there is no claim, unless agreement was impossible or impracticable (including where it is precluded by mistake), in which case the law may in some circumstances recognise a claim for payment. (3) For a contractual claim, the price is the agreed price, and if it is not explicitly agreed, it is the objective price, typically the market price. Where there is no agreement, and the law nevertheless allows a claim, the appropriate price is the subjective price, which may depart from the market price, at least for the benefit of the defendant (subjective devaluation). The outcome in Benedetti seems to be consistent with this scheme, according to which the claim should have been addressed as an issue in contract, and the measure was rightly objective, but of course this was not the approach taken by the court.

Now compare the scheme adopted from the unjust enrichment literature and applied in Benedetti. (1) Where there is an agreement meeting the conditions for a contract, there can be a contractual claim. (2) There can also be an unjust enrichment claim, which may arise in cases where agreement is impossible or impracticable but is not confined to such cases. (3) To the contrary, there can be an unjust enrichment claim on the ground of failure of consideration, which appears to be based on an agreement that may or may not meet the conditions for a contract. (4) The standard measure of recovery for an unjust enrichment claim is the objective measure of the benefit. (5) However, where relevant, for example in the case of a claim for payment for the supply of services, the standard measure is the subjective measure, at least for the benefit of the defendant (subjective devaluation). (6) However, where there was free acceptance, or possibly more narrowly where there was an agreement, as, it would appear, in a case of failure of consideration, the law reverts to the objective measure.

On the face of it, the problem with the unjust enrichment approach is that it leaves room for a claim for payment for services in the absence of an agreement, even though the parties could 
easily have made an agreement. This would be highly subversive of contract law and it is a matter for concern that the law may have reached this position. But the real problem arising from Benedetti is that, although the claim was in unjust enrichment, it was really based on an agreement. Indeed, I suspect that this unjust enrichment scheme generally delivers the same outcomes as the simpler more traditional contracted-oriented scheme, but it is complex and opaque. The underlying problem is that in a case like Benedetti the true justice of the claim lies in the principle of agreement, the principle that the parties to an agreement should be held to it, but instead of being dealt with through the law of contract the claim is forced into the unjust enrichment framework. This framework is constructed around the standard case of the recovery of a mistaken payment, and is not designed specifically for agreements, and so has to be adapted to take account of the true basis of the claim by the use of what are in effect disguised contractual concepts such as 'failure of consideration', 'free acceptance' and 'freedom to choose'. It is the mismatch between the form of the claim and its true basis that is the source of the unnecessary complexity and opacity of the law, and in Benedetti it was behind the problem of determining the appropriate measure, since this is liable to depend on whether the claim is really based on an agreement or not. This underlying problem is not confined to this type of case but arises whenever the law takes the form of a claim in unjust enrichment. The recognition of a law of unjust enrichment, with its own body of rules, and employing its own distinctive concepts, makes sense only on the assumption that there is a certain general principle of liability to provide a basis for it. In reality there is no such general principle, and the rules of unjust enrichment, though constructed around such a supposed principle, have to be adapted in different situations to give effect to whatever principle of liability is actually relevant in that situation. ${ }^{28}$

\footnotetext{
${ }^{28}$ Examples of this type of problem arising from the unjust enrichment fallacy are discussed in P Jaffey, Private Law and Property Claims (Oxford: Hart, 2007), ch 8.
} 